\title{
Policy in the Wake of the Banking Crisis: \\ Taking Pluralism Seriously ${ }^{1}$
}

\author{
Sheila C Dow
}

\begin{abstract}
This paper explores a pluralist approach to policy with respect to the financial system in the wake of the crisis. We consider first what is involved in a pluralist approach to policy more generally, and how this may be justified. This includes a pluralist stance with respect to different approaches to economic theory, pluralism in the sense of interdisciplinary enquiry, pluralism in terms of range of methods employed, and pluralism with respect to recognition of the plurality of culture and values in society. Implications are drawn for how the banking crisis is framed, how it is explained by theory and thus how policy is designed. In addressing these issues, current mainstream theory focuses on a narrow definition of rational behaviour which, within competitive markets, generates a socially-optimal outcome. This approach is governed by a mathematical formalist methodology, and encourages policy to incentivise this kind of rational behaviour, with respect for example to inflation targeting and addressing moral hazard. Pluralist theory would instead recognise the socio-psychological and institutional/evolutionary foundations of money and banking, such that policy needs to focus on rebuilding confidence and addressing moral (including distributional) issues. The relevant analysis would require a range of methods and would address pluralities within society.
\end{abstract}

Key words: pluralism, monetary policy, bank regulation JEL codes: B41 B50 E58 G28

\author{
SCEME \\ Division of Economics \\ University of Stirling \\ Stirling FK9 4LA \\ UK \\ Tel: +44-1786-467470 \\ e-mail: $\underline{\text { s.c.dow @stir.ac.uk }}$
}

July 2011

\footnotetext{
1 This paper has benefited from discussions in the 'Pluralism in Crisis' Workshops, Institute for Advanced Studies, Strathclyde University, summer 2010, following presentation to the Economic Policies for the New Economic Thinking Conference, St Catherine's College Cambridge, 14 April 2011, and from comments and suggestions from two anonymous referees.
} 


\section{Introduction}

The financial crisis dented confidence in standard economic theory. For some economists the answer lay in seeking a new standard analysis to replace the old. But others have argued that it is the very notion of an exclusive standard analysis which is problematic. Given the open nature of the subject matter, any analysis may turn out to be inadequate in an uncertain future. The more robust strategy then is to foster a range of theoretical approaches, theories and methods from which to draw in different circumstances, ie pluralism. Coherent practice, in theory and policy, requires the selection of one analysis or another. But it is the attitude to the selection which is important. For a monist this selection is definitive, ruling out alternatives. But for a pluralist this is a provisional selection from among an evolving range, and the selection requires justification. Policymakers may feel uncomfortable with an absence of analysis put forward confidently as 'correct'. But in the wake of the crisis they may appreciate pluralism more, since it would give a better sense of the range of feasible analyses and advisers would need to make the case for their own preferred analysis.

There has been much discussion in the non-mainstream literature about pluralism. Indeed pluralism has been identified, in the search for a way of defining heterodox economics, as a common characteristic on which a definition might be based (see eg Lee 2009). This is not uncontroversial - some avowedly heterodox economists arguably do not identify with pluralism (see eg Garnett's 2006 account). Nevertheless the idea of pluralism is sufficiently widely espoused, as evidenced by the extent of membership of the International Confederation of Associations for Pluralism in Economics (ICAPE), that we can take it as an important element in heterodox economics. 
The purpose of this paper is to move beyond an internal discussion about pluralism among heterodox economists in terms of variety of approach within economics. Specifically the aim is to consider what pluralism means at a range of levels and to consider how it translates into the practice of policy making. There has been some discussion of a pluralistic approach to policy on which we will draw (see eg Dow 2004b, van Dalen 2007, Downward and Mearman 2007, 2008, 2009). The aim is to draw these strands together and to include more of a focus on plurality in the economy itself. The context for this discussion is the financial and economic crisis which began with the banking crisis in 2007 and the recommendations which might be made by a pluralist economist, for both monetary policy and bank regulation. Discussion of such recommendations will refer as much to the process of policy design as to policies themselves.

The first task is to discuss the meaning of pluralism, something which has been the source of some confusion in the literature; plurality and pluralism can apply at a range of levels. We will in the process consider the case for pluralism at different levels. This discussion is followed by a comparison between mainstream analysis of the crisis and its cures on the one hand and a pluralist analysis on the other. This discussion includes reference to the methodologies respectively employed in the analysis and the procedures adopted for policy design.

\section{Pluralism: Meaning and Justification}

Pluralism has evolved as a philosophical concept and evades simple definition. Negru (2009) provides a valuable account of this evolution. But, since the aim here is to extend 
the application of pluralism to the practice of policy design, some further discussion of its meaning is required, at least in order to clarify the particular meaning being used here. As a first step it is useful to distinguish pluralism from plurality; the second refers to variety while the first refers to the advocacy of plurality (Mäki 1997). We will consider shortly why plurality might be advocated, but there is also the question of the object of plurality. At what conceptual level is plurality being addressed (see further Dow 1997)? The four levels on which we will focus are the ontological level (the level of reality), the epistemological or meta-methodological level (the level of approach to methodology), the methodological level (the content of methodology) and the level of practice. ${ }^{2}$

The most common level at which pluralism is discussed is at the level of approaches to knowledge: the epistemological level. At this level, methodological pluralism entails recognition and tolerance of a range of methodological approaches. A contrast is normally drawn with the monism of mainstream economics, which rests on a particular view of economics as a science with one preferred approach. This approach rests on the application of deductive logic and empirical testing against an undisputed, independent set of 'facts'. A pluralist approach in contrast questions the validity certainly the universal validity - of this form of logical positivism. Caldwell (1982) initiated the pluralism literature with his critique of positivism as a discredited philosophy of science. In particular empirical testing has been shown not to be conclusive.

A particular critique of mainstream monism has been the focus of Lawson's work.

He has demonstrated the problems posed by the mainstream requirement for deductive mathematical formalism and associated econometric testing. In particular he notes the

\footnotetext{
${ }^{2}$ We do not focus on pluralism at the level of theory on the grounds that all approaches generate a plurality of theories. While several commentators have identified pluralism in mainstream economics, what is generally meant is pluralism only at the theoretical level.
} 
failure of the Bourbaki project to construct a complete deductivist mathematical system which is independent of empirical input (Lawson 2009a, 96). But his argument specifically shifts attention away from this epistemological level to the ontological level. It is really at this level of reality that we should start our consideration of pluralism.

It is important to consider the nature and scope of variety in nature, where 'nature' in a social system includes such variables as habits, conventions and institutions as well as physical variables. The logical positivist approach to knowledge presumes uniformity in nature, such that laws may be discovered for universal application. While there is scope for different subjective perceptions of reality, these laws are open to empirical testing by econometric methods which presume that data emerge from a structure which is given or whose changes are incorporated in the model. The context is a formal model which purports to represent a full argument - hence the suggestion that what is required in response to the crisis is a better model (see Colander et al. 2008 and Lawson's 2009b critique).

The ontology which Lawson identifies as an alternative to the mainstream is one where event regularities are not the norm, because social systems are open. These systems evolve in non-deterministic ways, both as a result of the emergence of new forces affecting the system and also of evolving interactions within systems. While this is not the primary focus of his analysis, social systems involve variety - there is plurality (Lawson 2009a, 118-9). ${ }^{3}$ Similarly variety is entailed in Chick and Dow's (2005) open system framework, with its (permeable, provisional) subsystems. Plurality is evident in social systems in a variety of forms, beginning with the underlying causal tendencies. These are various, most obviously due to the differentiation between the legal,

\footnotetext{
${ }^{3}$ As we explore further below, the plurality of understandings is part of this plurality.
} 
institutional and cultural structures which pertain in different nation states and which impinge on economic relations. Most clearly in current circumstances these international differences have generated structural imbalances which threaten the stability of the international economy. There are also longstanding imbalances between living standards in rich and poor nations. These pose policy problems for individual governments in the international sphere. The Washington Consensus, which put forward universal solutions to international economic imbalances, has been widely challenged so that contextspecific solutions are increasingly being sought (Gay 2009). But even domestically policy-makers face important pluralities in terms of income distribution, economic power, economic opportunity, and increasingly in terms of the cultures and values of different groups. A social democracy is expected to generate policy which respects such variety but at the same time seeks to address imbalances of power and opportunity. Further, for clarification, social democracy relies on pluralism in the form of tolerance of different perspectives on ethical grounds.

Most discussions of pluralism in economics highlight uncertainty as a key feature of an open system which includes variety. Without uniformity of nature and the scope for laws to be identified, ie with ontological plurality, knowledge is held with uncertainty. Keynes (1921) made this argument originally in his Treatise on Probability in terms of the organicism, particularly of social systems. It is this argument in turn which underpins the plurality of approaches to knowledge, providing a strong case for methodological pluralism. If no one approach to knowledge can be demonstrated to be best, then there is scope for a range of legitimate approaches to knowledge, ie methodological plurality. Even if only one approach prevails in any one context, the scope for context to change 
unexpectedly means that other approaches need to be available to step into the breach. The justification is similar to the justification for biological diversity: it promotes systemic resilience in the face of unforeseen developments.

This plurality may refer to approaches to economics but also to different degrees and forms of recourse to other disciplines complementary to economics. While mainstream economics has increasingly looked to other disciplines, such as psychology and physics, it has done so by incorporating ideas from these disciplines into the monist methodological approach already employed for economic analysis. This is evident for example in the case of biology and complexity theory. Heterodox economics has instead taken different disciplinary approaches more seriously in a process of synthesis rather than absorption, as in the case of sociology and social economics, psychology and old behavioural economics, biology and old institutional economics and so on.

This pluralism with respect to approach in turn provides the basis for pluralism at the level of method, ie a pluralist methodology. Once we move away from the mainstream monist requirement of deductivist, mathematical formalism, there is a range of other methods of analysis and of gathering evidence which may be employed (Downward and Mearman 2009). It is to be expected (although not inevitable) that methodological pluralism involves not only acknowledgement of variety of approach under uncertainty but also recognition of the benefits of variety of method within any one approach as a way of dealing with uncertainty. Different methodological approaches select a particular range of methods suited to their approach, which in turn is suited to their particular (open-system) ontology. This argument has been developed in Dow 
(1997). We will find when we come to discuss the policy-making process below that the issue of plurality applies there too.

While generally we may expect the ontological position on monism or pluralism to carry over to meta-methodology, methodology and practice, this is not necessarily the case. There are some within heterodox economics who are methodologically monist (they recognise only one best approach) but who reject the mainstream form of monism in favour of a pluralist methodology, in the sense of openness to other disciplines and recourse to a range of methods beyond deductivist, mathematical formalism. This has been the object of pluralist critiques eg from Garnett (2008). Indeed McCloskey (1985) presents it as an empirical fact that even mainstream economists employ a range of methods in their 'unofficial discourse' (while the official discourse remains mathematically formalist). Even more when it comes to the practice of designing and implementing policy we find plurality (monetary policy consists of signalling as well as setting interest rates, financial regulation is deliberately over-determined, and so on). This supports the Humean conclusion from the inability to construct fully closed mathematical systems that mathematical deductivism is inevitably incomplete as a source of knowledge. Yet this plurality sits uneasily alongside the official monism.

In what follows we will consider plurality in the sense of variety of methodological approach and of content of methodology, as well as variety in the economic system. The implications of pluralism (the fostering of such variety) are then explored for the design and conduct of policy.

\section{Methodological Pluralism and the Banking Crisis}


We begin to develop a pluralist approach to policy in the wake of the crisis by considering methodological pluralism, ie the acknowledgement of different approaches to knowledge about the crisis. This reflects different understandings of the underlying reality (on the part of the diverse groupings in society). Approach to knowledge involves more than theory and indeed includes the way in which theory is understood. It begins with the way in which the reality is understood, from which circumstances and underlying forces are understood or framed by different groups in society and from which academic economic theory develops (see further Dow forthcoming, a). ${ }^{4}$ This is not the infinite variety of framing of the constructivist approach but a more structured variety, which in turn reflects social structures (Dow 2004a).

But as we have seen not all of these approaches are themselves methodologically pluralist. In particular the mainstream approach is monist in purporting to be the most 'scientific' approach, such that mainstream economics in fact is regarded by mainstream economists as synonymous with economics, such that 'less' scientific approaches may be dismissed. This follows from the mainstream ontology, within which the economic system is framed in a particular way. Methodological pluralists rather see mainstream economics as one approach among several, albeit one which is heavily critiqued and rejected by most.

Framing itself may or may not be pluralistic, depending on how far there is awareness and tolerance of alternative framings. It depends on personal experience, including what Searle (1995) refers to as 'deep background'. But while there is scope for individual experience to be important for framing, this experience is generally mediated

\footnotetext{
${ }^{4}$ Framing is a form of conceptualising complex reality and can take a variety of forms. In particular the economic theorist will employ a much higher level of abstraction than the non-theorist.
} 
and understood socially. Macroeconomics normally refers to a high degree of aggregation into functional groupings within which there is further variety. In order to illustrate how framings differ even between these functional sectors, we will restrict the discussion to this limited form of variety. Thus for example, within the social structure of the financial sector, the way in which market developments are understood is heavily conditioned, not only by conventional practices, but also by market sentiment. Markets are framed primarily in terms of prices as the outcome of market sentiment, including the pricing of risk, and only secondarily in terms of any underlying real economic activity (referred to as the 'fundamentals'). This contrasts with the household and business sectors, whose experience of financial markets includes their particular experience of the cost and availability of credit, experience with trading assets (notably housing in the case of households), and expectations about future financial conditions, conditioned by pronouncements by 'experts'.

Framing by policy-makers focuses on their own direct experience of financial markets. This has undergone a dramatic shift in the light of the banking crisis, before which many nations' authorities did not routinely track financial stability and problems of systemic risk, particularly as they impinge on the banking system. Policy-makers also frame financial markets in the light of expert opinion, including both market watchers and academic economists and finance theorists. Traditional mainstream theory of monetary policy framed the reality in a highly abstract way, abstracting in particular from banks and even (in the case of Woodford's, 2003, influential text) from money. In contrast, non-mainstream framing of the financial sector focused heavily on banks and money (see eg Arestis and Sawyer 2006) and on the endemic scope for financial 
instability (drawing especially on the work of Minsky). It is only with the crisis that any meaningful recourse has been made by policy-makers to this latter literature, such that it has impinged on policy-makers' framing.

Framing issues arise because of the complexity of reality, which means that all knowledge is at best partial. But it is not a matter just of a reality overlaid by subjective knowledge. Framing also becomes part of the reality, ie it is performative. This follows from the opinion of others entering into framing by particular groups. Thus for example expectations can be self-fulfilling. A loss of confidence on the part of depositors with Northern Rock exposed the potential fragility of other banks' portfolios and translated into a more general loss of confidence. Even when there is good reason to have confidence in a bank's portfolio for other reasons, a loss of confidence by others becomes a compelling reason to share it and to act upon it.

Not all framings have an equal impact on reality, since there is unequal power in the economy. Thus households and small and medium-sized enterprises are dependent on terms for credit set by banks and on swings in market valuations on which they have no impact. Policy-makers have formal power over regulation and monetary policy, but in practice market sentiment and the lobbying power of the financial sector operate as substantial constraints on what the authorities can do. The financial sector's framing is thus critical, as evidenced by the impact on policy of their views as to the acceptable size of public sector deficits.

The financial sector's framing differs from the abstractions of traditional mainstream academic framing, in that the latter is highly abstract and focuses on equilibrium outcomes. Yet that theoretical framing also lent academic support to the view 
that free market forces in the financial sector produce optimal outcomes and was adduced in support of financial sector lobbying for deregulation, notably in the 1980s. It also provided the foundation for mainstream finance theory, which presumed to be able to identify the value of assets, including the risk attached to future values, something which accords with a framing of the underlying reality in terms of given structures and law-like behaviour. The highly complex risk modelling developed by financial institutions, much of it spurred on by the information needs of the capital adequacy requirement regime, was built on this finance theory, cementing mainstream finance framing into the institutional arrangements of the financial sector. This framing was further cemented in the institutional design of the policy-making framework, with central bank independence and separate regulatory authorities reflecting a theoretical separation of these functions and, in the case of the European Union, the Growth and Stability Pact.

\section{Explanations for the Crisis and Policy Recommendations}

These different framings provided the basis for the different explanations of the crisis and for policy responses. Mainstream theory frames the financial sector as a competitive market which generates a socially optimal outcome, where the authorities set a benchmark nominal interest rate and to implement a regulatory framework which potentially distorts that market. Behaviour is understood as rational in the sense of the application of deductive logic on the basis of certainty equivalence. The mainstream framing homogenises this behaviour across different sectors, cultures, etc by expressing it as the rational pursuit of self-interest in response to financial incentives. Such behaviour, 
which maintains market equilibrium, is treated as law-like according to a monistic view of reality and a monistic, deductive, mathematical methodology.

Instability in financial markets challenges this framing. But the framing can be adapted by incorporating impediments to equilibrating behaviour. These impediments include market imperfections, such as regulation which, according to mainstream theory, distorts market behaviour and creates information asymmetries. The current crisis followed a period of significant deregulation, but the moral hazard created by the continuing expectation of central bank support for failing banks has been identified as a key explanation for the excessive build-up of risk by banks (see eg Dowd 2009). A second focus has been put on information asymmetries such as those arising from opaque, structured products and from credit ratings by agencies incentivised to distort information. This New Keynesian version of mainstream framing shares with other mainstream approaches the view that a unified reality yields certain information in principle, even though in practice this may be concealed from some parties. Some plurality is therefore identified in the particular instantiation of information asymmetries, but the aim is to restore a unified certainty equivalence. The third category of impediment to equilibrating forces is irrational behaviour, something normally associated in mainstream theory, if admitted at all, with non-specialist market players. Irrationality is understood as short-term emotion overriding long-term rationality. There has been more general discussion of irrationality as possibly extending also to market players, as an explanation for the strong rise in asset prices and under-pricing of risk up to 2007 and the subsequent sharp reversals. 
This framing of the causes of crisis suggests clear policy solutions. The solution to moral hazard is seen as either withdrawing the lender-of-last-resort altogether and replacing fractional reserve banking with 100\% reserve banking (see Kotlikoff 2010) or limiting it to a much narrower class of banking operations, but still allowing the possibility of an ordered bank failure. ${ }^{5}$ The solution to information asymmetry is to reduce it by requiring more transparency with respect to structured products and a change in the incentives facing credit rating agencies. The solution to irrationality is measures to 'nudge' behaviour towards rationality (Thaler and Sunstein 2008). The underlying framing of behaviour as narrowly rational produces policy solutions which rely on financial incentives in order to alter behaviour.

A pluralist perspective approaches the issue of understanding the causes of crisis in a quite different way. We focus here on a Post Keynesian pluralist perspective, although many of the arguments are made also by other heterodox schools of thought. It is methodologically pluralist in incorporating the role of mainstream economic thinking in the emergence and analysis of the crisis. It is also pluralist in the methodology employed, drawing on history, sociology and psychology without trying to homogenise them within a single formal framework.

Starting from an understanding of the essential uncertainty of knowledge about a diverse, evolving reality, this approach understands the context of crisis in these terms. It seems that social structures, including the state, have emerged and evolved over time in order to facilitate decision-making under uncertainty. A key element of these structures is money and the banks whose liabilities societies predominantly use as money. Central banks evolved to support banks in such a way as to promote confidence in bank

\footnotetext{
${ }^{5}$ The term 'narrow banking' is confusingly applied to both types of system.
} 
liabilities. In exchange for the profitable opportunities this provided for banks to create credit in a fractional reserve system, the banks accepted the restrictions on their activities set by central banks. The system succeeded because trust was built up over the years between banks and central banks on the one hand and between banks and the public on the other. This generated generalised confidence in money.

But this process worked in different ways in different economies and has been subject to different challenges, albeit following a common logic (Chick 1986). In the case of the current crisis the banks had succeeded in encouraging a process of deregulation which (according to mainstream economic logic) freed them from their traditional obligations. They increased their leverage and took on assets whose riskiness was not understood, along with other financial institutions, all encouraged by the mainstream view of financial markets as equilibrating around correct prices. The Post Keynesian view in contrast is that there are no 'correct' prices, only prices that bear more or less relation to any underlying real assets. Rather assets are priced under uncertainty, with behaviour involving an integrated combination of reason and sentiment (given the limited scope for deductive reasoning under uncertainty) (Dow forthcoming, a). Inevitably market sentiment is prone to swings. A stable upward swing in particular, which mainstream theory interprets as an equilibrium phenomenon, is evidence of increasing fragility according to Minsky's financial fragility hypothesis. Minsky refused to model his hypothesis as something deterministic, since each cycle is associated with its own particularities, including the timing of reversals of sentiment. The origins of the recent crisis were therefore identified with the emergence of particular new products and practices, and therefore the crisis broke in different ways in different economies. In the 
UK it broke when other banks refused to fund Northern Rock's assets, uncertainty spread to the assets of other banks and the interbank market froze (Chick 2008). The previous diffuse confidence in money was severely threatened, and the focus returned to the particular agency of key institutions and individuals - the crisis became one of trust (Hughes 2011).

Given this analysis of the crisis, the Post Keynesian policy response is addressed to the products and practices which, combined with the swing in market sentiment, led to the breakdown in financial markets when the crisis broke. Given that mainstream theory and policy had lulled markets into a false sense of confidence, uncertainty was high surrounding the breakdown in that confidence and in the ability of markets to price assets. Policy was needed to restore confidence, based in practice on active regulatory and supervisory measures to rein in bank behaviour and, crucially, active central bank support for banks and reassurances of continuing support. Given the diversity of forces affecting banks and confidence in banks, and uncertainty about these forces, there needs to be over-determination in central bank support (a 'belt-and-braces' approach): regulation, supervision and monitoring; lender-of-last-resort support should that not be enough; and a clear deposit insurance scheme are all needed to reassure depositors in case their confidence in that support should waver.

In line with a pluralist analysis goes an understanding of the scope for complex interactions between policy on bank regulation and monetary policy (and indeed fiscal policy). This contrasts with the clear separations of abstract mainstream analysis which have encouraged clear institutional and policy separations (the latter taking the form of one instrument per target). Where money is regarded, as in Post Keynesian theory, as 
endogenous through the credit creation process, and even central bank interest rates are endogenous to market expectations, ${ }^{6}$ central bank interest rate policy has only very indirect effects on inflation - and indeed these effects may operate perversely more through costs (to the extent that bank lending rates follow central bank rates) than any effect on aggregate demand.

The scope for active monetary policy, beyond the provision of liquidity to avert the immediate crisis, is in any case very limited in a recession. The authorities have attempted to enforce low rates through open market operations (dubbed 'quantitative easing'), yet, while rates on gilts responded, actual loan rates have remained high. More problematic has been the unwillingness of banks to increase loans as they aim to restructure their balance sheets. 'You cannot push on a string.' The emphasis therefore remains on signalling the direction in which the authorities would like to see markets taking than any direct effect of interest rate policy. Analysis and pronouncements are as important as, if not more important than, setting the interest rate. To the extent that central banks draw on mainstream theory of monetary policy these pronouncements serve to further embed a mainstream framing of the policy agenda.

But a Post Keynesian framing draws more on a focus on the institutional and behavioural evolution which brought us to the present situation and the role of the state in influencing this evolution in the future. While the framing of mainstream theory has focused on behaviour as an individualistic phenomenon (rational or irrational), Post Keynesian theory focuses rather on social norms and conventions which cannot be explained fully by response to financial incentives. The current degree of public

\footnotetext{
${ }^{6}$ Interest rate policy depends on the markets' expectations of what the central bank will do; these expectations are inputs to the forecasts on which monetary policy is based.
} 
ownership of banks in the UK in the wake of the crisis affords a tremendous opportunity for government to forge change in the behaviour of financial institutions.

The framing of the crisis by the general public has focused on experience: the fiscal consequences of bank bailouts, which are causing hardship through layoffs, increased taxes, reduced public services, reduced pensions and pay limitations; reduced availability and higher cost of credit; and highly publicised bonuses in the financial sector. The response has been one of moral outrage which can only be explained partly in terms of self-interest; it reflects also a concern with social justice. Mainstream economics considers normative issues as applying only at the policy-design stage of analysis, regarding the underlying theory as value-free. Mainstream theory therefore aims to defuse distributional concerns with arguments about the importance of financial incentives as a universal requirement of a socially optimal economic system. In contrast Post Keynesian theory takes distributional concerns seriously as an integral element of the policy response. Further, if part of the policy response to the crisis is to aim to change social norms, it is critical that the concerns and understandings of different segments of society are taken seriously rather than being dismissed as necessarily 'emotional' or 'irrational'. Distributional concerns are not separable as 'politics' or 'psychology', bat are part of the subject matter of economics designed to inform policy.

\section{Pluralist Policy Implementation}

A monistic approach to policy, as in its mainstream textbook form, is for singular solutions to emerge from a model of the economy. Thus for example a macroeconomic model yields a unique recommended official interest rate addressed to an exogenously-set 
inflation target. Given the monistic, deductivist, mathematical methodology of mainstream economics, the model's recommendation is definitive. The standard macroeconomic model has already incorporated the different sectors in the economy and rests on the fiction of the representative agent. While the latter is something increasingly open to question by New Keynesian economists as some plurality in society is introduced (see eg Stiglitz 2010), this limited plurality is still homogenised according to the rationality assumption and the benchmark of complete information to which some groups may have limited access.

The political and bureaucratic process by which the policy recommendations of such models are translated into practice is not regarded as the economist's business. This attitude reflects further the associated positivist view that economists can and should restrict their recommendations to positive arguments based on 'objective' models; it is the business of politicians then to apply normative judgement.

A methodological pluralist approach would challenge such a stance. The nature of the economic system is seen to be such as to be characterised by uncertain knowledge hence the stance of methodological pluralism and also pluralist methodology. No one formal model can be capable of presenting a complete policy argument; any model can only present partial arguments to be considered alongside other types of argument. Further endemic uncertainty undermines the mainstream concept of rationality, such that reason in a pluralist framework operates in conjunction with social convention and emotion, including value systems (Dow 2011). Given plurality in social structures, including plurality of cultural norms within any one society, and an imbalance of power between different groups in society and therefore in the potential to impose particular 
value systems, social behaviour is heterogeneous in a complex way. There is scope for modelling some of this heterogeneity, but only as input to a more pluralistic analysis. Further, given the impossibility of disentangling values from the economist's depiction of the economic system, normative elements pervade any analysis (Fine 1980). The economist is inevitably engaging in political economy. The process of choosing and implementing policy is therefore part of the business of economics.

A methodological pluralist acknowledges the scope and need for a variety of approaches to economic analysis leading to policy recommendations. Yet a methodological pluralist who is also a practising economist must choose one approach or another to be coherent (and also to communicate successfully); to draw on a range of approaches is either to be incoherent or to develop a coherent new synthetic approach. Each approach is grounded in a particular ontology, from which follows an epistemology and methodology. These categories of course are not hard and fast, nor are they welldefined.

But what of government? Political parties belong to a similar type of classification, which includes diversity as well as permeable and evolving borders, and yet which serves a useful practical purpose. Government by one party therefore adopts one approach as the basis for policy. Yet politics involves the recognition of other approaches in the form of other parties, as well as the more general plurality within society. Indeed one role of government is to recognise plurality where some groups are more vulnerable than others and therefore more in need of protection by the state. At the same time governments themselves are subject to the power of external forces to which they must pay attention. In the case of the crisis the most relevant external force has been 
the financial sector, both domestically and internationally. This power stems not just from sheer size of balance sheets, but from the power of market sentiment. Under uncertainty there are no true prices as a reference point for markets. Market valuations, and in particular large swings in valuation, are the outcome of conventional judgement. Historical experience demonstrates the capacity for market sentiment to switch dramatically depending on judgements as to government policy, constraining governments dependent on bond finance and on the health of their financial sector. Nevertheless, while a particular political approach to policy inevitably reflects awareness of the significance of other groupings' analysis, and government rhetoric may not be consistent with policy practice, government must adopt one approach or another.

The monist, mainstream, academic literature provided an escape route of sorts from the need to address plurality by representing policy, especially monetary policy, as a purely technical matter to be handled by an independent central bank charged with addressing a politically-derived inflation target (Gabor 2010). Yet the technicalities proved to be challenging in the light of a loss of confidence on the part of policy-makers that any one formal model might be sufficient grounding for policy. Central banks explicitly draw on academic research on monetary policy and indeed produce their own academic research in house. Recent research has focused on the substantive issue facing central banks of model uncertainty, ie uncertainty as to which is the correct, or best, economic model on which to base monetary policy. However the mainstream academic approach to addressing model uncertainty was to model it in terms of a complex error process, which still allowed a unique policy recommendation to be generated (Dow 2004b). This contrasted with analysis coming out of central banks themselves, which 
reflected the fact that the modelling approach does not address fundamental uncertainty as to how best to model the economy.

Uncertainty has been a recurring theme in a range of speeches by members of the Monetary Policy Committee (MPC) of the Bank of England, including the Governor. The MPC went further in their publication on modelling which they introduced by explaining the need for models to be supplemented by judgement, ie by pointing out the limitations of the monistic, mainstream modelling approach (Bank of England 1999). Indeed they explicitly advocated a pluralist approach, whereby judgement would be applied to a range of models, each of which would be treated as presenting partial arguments.

Downward and Mearman (2008; see also 2007 and 2009) have explored the practice of arriving at policy decisions in the Bank of England in terms of triangulation. This can be understood as a pluralist methodology which accords with Keynes's (1921) notion of weight of argument. According to Keynes, the weight of an argument increases the greater the relative amount of relevant evidence which supports it. Thus if most different lines of reasoning support a policy of reducing the official interest rate, the weight attached to that policy is greater. Triangulation operates at a range of levels. It can refer to variety with respect to any or all of data, investigators, theoretical perspectives and methods. Downward and Mearman find evidence of triangulation on the part of the MPC, but recommend more effort in triangulation in terms of method; in spite of the profession of pluralism, there is still significant reliance on the Bank's core macro model. There is more scope for triangulation also in terms of theoretical perspectives. The increasing incidence of members of the MPC with strong mainstream academic backgrounds arguably has increased the focus on mainstream, monist epistemology and 
methodology; this focus sits at odds with the statements (such as support for pluralism) which reflect the actual conditions of uncertainty facing decision-makers.

The phenomenon of decision-making by committee has also become an object of study, of interest in relation to the mainstream depiction of a unified application of the results of a single model (see for example Gerlach-Kristen 2006). In the mainstream literature committees are depicted as enhancing decision-making because no one member has perfect knowledge. Each member of a committee brings their own analytical skills and particular data sets, improving the knowledge base of the committee as a whole. Some studies identify different preference functions (value sets) on the part of different members, although this becomes less relevant the more prevalent becomes the external setting of particular targets.

Mention is made in some studies also of variety of approach, although it is not explored. This variety appears to be understood in the mainstream literature as being variety within the monistic, mainstream approach, ie not grounded in an epistemology which emphasises uncertainty. This is evident from the association of variety in voting with uncertainty. Yet from a heterodox point of view variety of opinion may naturally emerge from variety of methodological approach, whether or not uncertainty is high. Similarly a committee representing different approaches might agree on a policy (normally 'no change') when the sense of high uncertainty is shared across approaches (see Dow, Klaes and Montagnoli 2009a and 2009b for some empirical evidence).

But it is important to note another feature which has returned to the monetary policy literature, which emphasises the role of signalling as an important tool of monetary policy (Dow, Klaes and Montagnoli 2007). This has arisen because of the New 
Keynesian emphasis on transparency as the best tool to counteract asymmetric information (see Geraat's 2002 survey). If the central bank is transparent about its analysis and expectations then financial markets can factor this into their own expectations of monetary policy. The aim of monetary policy is no longer to shock markets but rather to align public sector and private sector expectations. Any change in the official rate should be anticipated by financial markets. The rhetoric of that signalling is thus founded on a mainstream methodological approach, purporting to measure uncertainty within a unified modelling approach, even though the measures themselves may instead reflect collective judgement on the part of the MPC. Reference to mainstream theory and modelling appears to be persuasive in financial markets. But central bank signalling also reflects ontological and methodological plurality within the economy. Thus press statements may be addressed to the household sector, eg to dampen expectations of continuing rises in house prices, or to the business sector in speeches by MPC members to private sector organisations.

While policy with respect to regulation of the financial sector over the last 30 years has been treated as a micro issue, separable theoretically and institutionally from monetary policy, the crisis has changed all that. As discussed above, the pluralist Post Keynesian analysis of the crisis emphasises the inevitability of the increased fragility of the financial system as leverage increased and expectations of continued asset price rises became embedded, supported by mainstream finance theory. The disconnect between the epistemological foundations of that theory and actual experience had real consequences; variety of methodological approach matters. It matters further in policy making, when monetary policy relies on signalling in different ways to different constituencies. 
But communications with the general public have been mired in quite other issues surrounding the regulation of banks and the remuneration of bankers. The public's framing of the problem is in terms of fairness and morality. It is understood to flout social justice for the banks, which were seen as responsible for the crisis, the bailout, the recession and the ensuing cuts in the public sector, not to be more strictly controlled and for bankers to receive what are by most standards to be enormous financial rewards. This framing does not accord with the mainstream framing in terms of rational responses to financial incentives and thus is disregarded. Yet if banks and central banks are institutions which have evolved cooperatively to provide for society's needs for the provision of a safe asset and of credit, and if the entire system is based on the confidence built up over centuries, then changing financial incentives is not by itself going to restore confidence. What is required instead is a focus on the conventions followed in the financial sector and the relationships between public and private sectors, requiring a pluralist methodology.

\section{Conclusion}

We have emphasised here the important for policy of an increased recognition of the plurality in society, as well as the scope also for more pluralism in terms of epistemology and methodology. Policy-making committees like the MPC would benefit from representation from a variety of different methodological approaches, as well as a more explicit variety of methods. But this also requires recognition that neither monetary policy nor regulatory design is only a technical matter. Rather they are exercises in political economy; there needs to be recognition that different approaches to designing 
policy recommendations accord with different political stances, so that it is appropriate for a government to choose policy which fits with their own approach. Nevertheless, since policy is addressed to a pluralistic society and is understood according to the framings of different groupings, it is important to recognise these different framings if government aims to influence behaviour. Further, policy making is more resilient if governments cast their analytical nets wider than one apparently best' approach. No one approach can offer a complete account, so much can be learnt from attending to alternative accounts.

\section{References}

Arestis, P. and M. Sawyer (eds). 2006. Handbook of Alternative Monetary Economics. Cheltenham: Edward Elgar.

Bank of England. 1999. Economic Models at the Bank of England. London: Bank of England.

Caldwell, B. 1982. Beyond Positivism. London: George Allen \& Unwin.

Chick, V. 1986/1992. The Evolution of the Banking System and the Theory of Saving, 
Investment and Interest. Economies et Sociétés, serie Monnaie et Production no. 3: 11126. Reprinted in On Money, Method and Keynes, ed. P. Arestis and S.C. Dow, 193-205. London: Macmillan.

Chick, V. 2008. Could the Crisis at Northern Rock have been Predicted?: An Evolutionary Approach. Contributions to Political Economy 27 no. 1: 115-124.

Chick , V. and S.C. Dow. 2005. The Meaning of Open Systems. Journal of Economic Methodology 12, no. 3: 363-81.

Colander, D., H. Föllmer, A. Hass, M. Goldberg, K. Juselius, A. Kirman, T. Lux, and B. Sloth. 2008. The Financial Crisis and the Systemic Failure of Academic Economics.

mimeo, available at http://www.debtdeflation.com/blogs/wpcontent/uploads/papers/Dahlem_Report_EconCri sis021809.pdf

Dow, S.C. 1997. Methodological Pluralism and Pluralism of Method. In Pluralism in Economics, ed. A Salanti and E Screpanti, 89-99. Cheltenham: Edward Elgar.

Dow, S.C. 2004a. Structured pluralism. Journal of Economic Methodology 11, no. 3: 275-90. 
Dow, S.C. 2004b. Uncertainty and Monetary Policy. Oxford Economic Papers 56: 53961.

Dow, S.C. 2011. Cognition, Sentiment and Financial Instability: Psychology in a Minsky Framework. Cambridge Journal of Economics 35, no. 2: 233-50.

Dow, S.C. forthcoming, a. 'Framing Financial Markets: A Methodological Approach', in W Oostwouder, W and H Schenk (eds), Governance of the Modern Firm under Financial Turbulence, Cheltenham: Elgar.

Dow, S.C. forthcoming, b. Keynes on Knowledge, Expectations and Rationality. In Microfoundations for Modern Macroeconomics, ed. E S Phelps and R Frydman. Princeton NJ: Princeton University Press.

Dow, S.C., M. Klaes and A. Montagnoli. 2007. Monetary Policy by Signal. In Open Market Operations and the Financial Markets, ed. D.G.Mayes and J. Toporowski. London: Routledge.

Dow, S.C., M. Klaes and A. Montagnoli. 2009a. Variety of Economic Judgement ans Monetary Policy-making by Committee. In Macroeconomic Policies on Shaky Foundations: Whither Mainstream Economics?, ed. E. Hein, T. Niechij and E. Stockhammer. Marburg: Metropolis-Verlag. 
Dow, S.C., M. Klaes and A. Montagnoli. 2009b. Risk and Uncertainty in Central Bank Signals: An Analysis of Monetary Policy Committee Minutes. Metroeconomica 60, no. 2: 584-618.

Dowd, K. 2009. Moral Hazard and the Financial Crisis. Cato Journal 29, no. 1: 142-66.

Downward, P. and A. Mearman. 2007. Retroduction as Mixed-Methods Triangulation: Reorienting Economics in Social Science. Cambridge Journal of Economics 31, no. 1: 77-99.

Downward, P. and A. Mearman. 2008. Decision Making at the Bank of England: A Critical Appraisal. Oxford Economic Papers 60, no. 3: 385-409.

Downward, P. and A. Mearman. 2009. Reorienting Economics through Triangulation of Methods. In Ontology and Economics: Tony Lawson and his Critics, ed. E. Fullbrook, 130-41. London: Routledge.

Fine, B. 1980. Economic Theory and Ideology. London: Edward Arnold.

Gabor, D. 2010. Central Banking and Financialization. London: Palgrave Macmillan.

Garnett, R.F. 2006. Paradigms and Pluralism in Heterodox Economics. Review of Political Economy 18, Fall: 521-46. 
Gay, D. 2009. Reflexivity and Development Economics. London: Palgrave Macmillan.

Geraats, P. 2002. Central Bank Transparency. Economic Journal 112, no. 483: F532F565.

Gerlach-Kristen, P. 2006. Monetary Policy Committees and Interest Rate Setting. European Economic Review 50, no. 2: 487-507.

Hughes, P. 2011. Trust: Economic Notions and its role in Money and Banking. University of Stirling PhD thesis.

Keynes, J.M. 1921. A Treatise on Probability. Collected Writings volume VIII. London: Macmillan, for the Royal Economic Society, 1973.

Kotlikoff, L.J. 2010. Jimmy Stewart is Dead - Ending the World's Ongoing Financial Plague with Limited Purpose Banking. New York: John Wiley and Sons.

Lawson, T. 2009a. Heterodox Economics and Pluralism: Reply to Davis. In Ontology and Economics: Tony Lawson and his Critics, ed. E. Fullbrook, 93-129. London: Routledge.

Lawson, T. 2009b. The current economic crisis: its nature and the course of academic economics. Cambridge Journal of Economics 33: 759-77. 
Lee, F. 2009. A History of Heterodox Economics: Challenging the mainstream in the twentieth century. London: Routledge.

McCloskey, D.N. 1985. The Rhetoric of Economics. Brighton: Wheatsheaf.

Mäki, U. 1997 The One World and the Many Theories. In Pluralism in Economics, ed. A. Salanti and E. Screpanti, 37-47. Cheltenham: Edward Elgar.

Negru, I. 2009. Reflections on Pluralism in Economics. International Journal of Pluralism and Economics Education 1, nos 1-2: 7-21.

Searle, J. 1995. The Construction of Social Reality. New York: Free Press.

Stiglitz, J. 2010. Agenda for Reforming Economic Theory. Presentation to inaugural INET conference, Cambridge, April, available at http://ineteconomics.org/video/conference-kings/agenda-reforming-economic-theoryjoseph-stiglitz

Thaler, R.H. and C.R. Sunstein. 2008. Nudge: Improving Decisions About Health, Wealth and Happiness. New Haven CT: Yale University Press.

Van Dalen, H.P. 2007. Pluralism in economics: A Public Good or a Public Bad?. In Teaching Pluralism in Economics, ed. J. Groenewegen. Cheltenham: Edward Elgar. 
Woodford, M. 2003. Interest and Prices: Foundations of a Theory of Monetary Policy.

Princeton NJ: Princeton University Press. 